대구경-후판 압력용기용 저 합금강 $(\mathrm{Mn}-\mathrm{Mo})$ 의 용접특성

\author{
안 종 석*,+ \\ "한국동서발전(주) 발전처
}

\title{
A Welding Charactenistics of Large Caliber-Thick Plate Pressure Vessel Low Alloy Steel (Mn-Mo)
}

\author{
Jong-Seok Ahn*, ${ }^{*}$ Jin-Keun Park* and Jae-Yeon Yoon* \\ *Power Generation Division, Korea East-West Power CO., LTD.
}

†Corresponding author : ahnjs001@ewp.co.kr

\begin{abstract}
Recently the low alloy steel plate made with manganese-molybdenum is used widely in steam drum and separator of the new coal-fired power plant boiler. This material is suitable for the vapor storage of high pressure and high temperature. The high temperature creep strength of Mn-Mo alloy is higher than the carbon plate(SA516) that used in the subcritical pressure boiler. It reduces the thickness of the pressure vessel and makes the lightweight possible. Recently in the power plant boiler operation and production process, the damage has happened frequently in the heat affected zone and base material according to the hydrogen crack and delayed crack. This paper describes the research result about the damage case experienced in the boiler steam drum production process and present the optimum manufacture method for the similar damage prevention of recurrence.
\end{abstract}

Key Words : Welding, Heat affected zone, Hydrogen crack, Delayed crack, Steam drum, Shield metal arc welding, Flux core arc welding

\section{1. 서 론}

국내 신규석탄화력 보일러 스팀분리기 및 증기 드럼 에서 사용하는 대구경-후판 압력용기 소재로 고온·고 압의 증기저장에 적합한 망간-몰리브덴 저 합금강판 (SA302B)을 최근 많이 사용하고 있다. 이전에 건설된 아임계압 보일러에서 주로 사용하였던 탄소강판(SA516) 보다 Creep강도가 월등히 높고 압력용기 두께감소로 인한 경제성측면에서 우수한 점을 고려하여 스팀분리기 및 스팀드럼 소재로 광범위하게 사용되고 있다. 하지만 국내 발전용 보일러 운영 및 제작과정 중에 Shell과 Nozzle(SA105)의 용접부에서 수소균열 (hydrogen crack, delayed (rack) ${ }^{1}$ 과 응고수축 균열 ${ }^{2}$ 로 인한 손상이 발생되었고 균열은 용접열영향부에서 모재까지 진행되었다. 논문에서는 대구경-후육 철판용접에서 전
통적으로 사용되었던 탄소강판과 신규소재의 용접 특성 비교 검토와 미세조직, 경도분석 시험을 통해 손상원인 분석 및이를 토대로 최적의 작업공정을 제시하였고 유 사손상 재발방지를 목적으로 논술하였다.

\section{2. 소재 특성 및 제작공정 고찰}

\section{1 스팀드럼 규격 및 화학성분}

본 연구에서 인용한 $\mathrm{SA} 302 \mathrm{~B}$ 소재는 후판압력용기 저 합금강판으로 국내에서는 초초 임계압 보일러의 고 온·고압 압력용기에 사용하고 있다. 비교대상으로 인 용한 탄소강판(SA516-60)은 과거 아입계압 보일러 압 력용기로 주로 사용하였고 제작 및 운전과정에서 수소 균열과 ${ }^{1)}$ 재열균열 $(\mathrm{reheat} \mathrm{crack})^{2)}$ 에 의한 손상이 일 부보고 되었으나 용접 성이 양호하여 손상보고는 많지 않았다. 

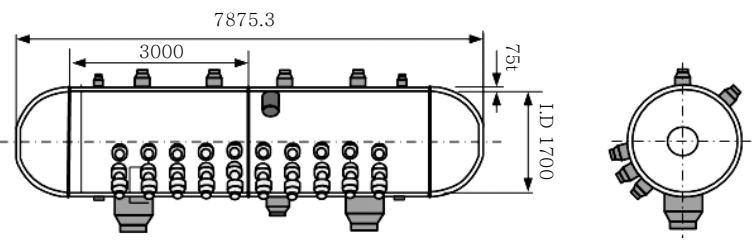

Fig. 1 The shape of steam drum shell and nozzle

제작과정 중에 손상된 스팀드럼의 규격은 I.D 1,700× $7875.3 \mathrm{~L} \times 75 \mathrm{t}$ 이며 사용설계 스팀압력 및 온도는 각각 117.2Bar, $324^{\circ} \mathrm{C}$ 이고 Shell 및 Nozzle의 형상은 Fig. 1에서 나타내었다.

Shell재질은 SA302B이며 Nozzle재질은 SA105이 고 비교재질인 SA516과 Table 1에서 화학성분을 Table 2에서 기계적 특성을 각각 나타내었다. SA302B 는 $\mathrm{Mo}$ 및 $\mathrm{Mn}$ 이 주요원소로 포함된 저합금강판이며, 압연상태에서 노말라이징(Normalizing) 시행 후 공급 되고 화력발전소에서는 주로 $420^{\circ} \mathrm{C}$ 미만의 증기온도에 서 사용되고 있다. 노즐(Nozzle)소재인 SA105는 고온 용 탄소강관으로 고온강도 향상을 위해 $\mathrm{Ni}, \mathrm{Cr}, \mathrm{Mo}$ 등이 포함되어 있으며 화력발전소에서는 $450^{\circ} \mathrm{C}$ 미만의 증기온 도에서 사용되고 있다. 연구에서 비교대상인 SA516Gr60 은 일반 탄소강재로서 고온강도 향상을 위한 합금원소 는 포함되어 있지 않아 중·고온용 강판으로 $400^{\circ} \mathrm{C}$ 미 만의 증기조건에서 사용되고 있다.

\section{2 미세조직 및 고온 강도특성}

Fig. 2 및 Fig. 3에서는 SA302B 및 SA516-60와 유사소재의 연속냉각곡선(continuous cooling transfor-

Table 2 Comparison of mechanical properties for the materials

\begin{tabular}{|c|c|c|c|c|}
\hline Material & $\begin{array}{c}\text { YS } \\
(\mathrm{MPa})\end{array}$ & $\begin{array}{c}\text { TS } \\
(\mathrm{MPa})\end{array}$ & $\begin{array}{c}\text { E.I } \\
(\%)\end{array}$ & 비고 \\
\hline SA302 Gr B & $345 \sim$ & $550 \sim 690$ & $15 \sim$ & \\
\cline { 1 - 3 } SA516 Gr60 & $220 \sim$ & $415 \sim 550$ & $21 \sim$ & \multirow{2}{*}{ ASME } \\
\cline { 1 - 3 } SA105 & $275 \sim$ & $485 \sim$ & $16.5 \sim$ & \\
\hline
\end{tabular}

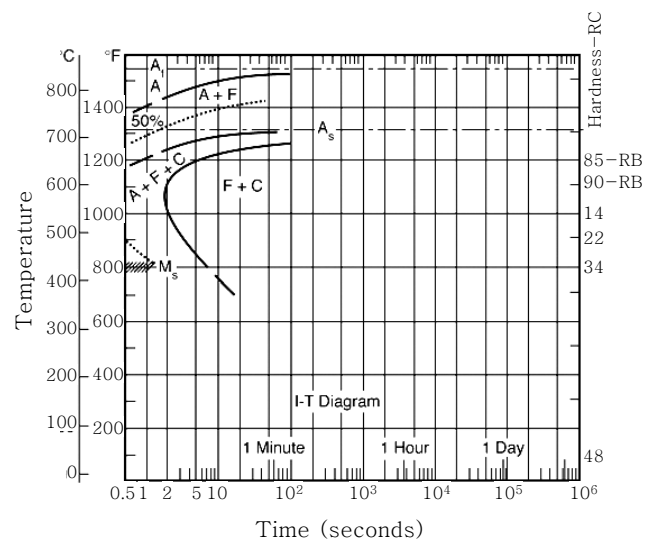

Fig. 2 AISI 1010(0.5wt \% Mn \& Mo CCT diagram

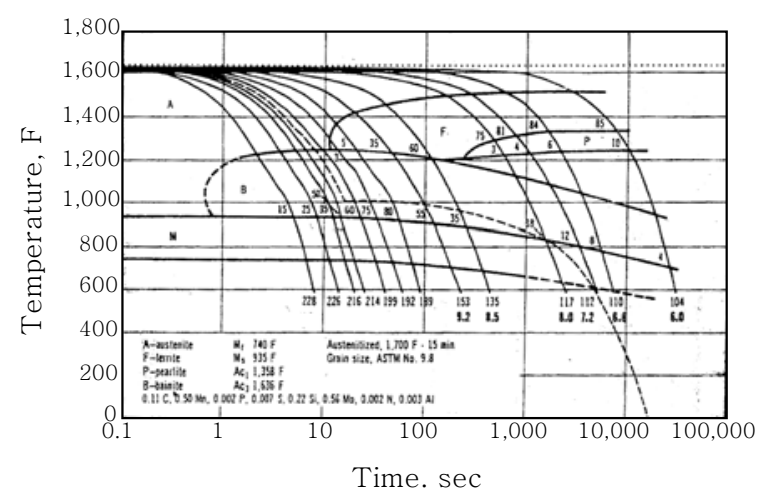

Fig. 3 SAE1021(0.2wt\% C) CCT Diagram

mation)을 각각 표시하였고 Fig. 4와 Fig. 5에서는 표 준조직을 각각 나타내었다.

$\mathrm{SA} 302 \mathrm{~B}$ 의 표준조직은 페라이트(ferrite)와 베이나 이트(bainite)의 혼합조직이며 냉각속도가 빠를수록 베 이나이트 및 마르텐사이트(martensite) 점유비가 커지 고 경도는 높아진다. 용접금속은 기본적으로 베이나이 트 조직을 나타낸다.

또한 SA516 소재는 페라이트와 퍼얼라이트(pearlite) 의 혼합조직이며 냉각속도가 빠르게 되더러도 같은 조 직을 유지하며 낮은 경도를 유지하여 연성이 큰 조직임 을 알 수 있다.

설계된 증기저장 온도 구간에서( $324^{\circ} \mathrm{C}$ 지점)의 $\mathrm{SA} 302 \mathrm{~B}$ 와 SA516 최소허용응력은 Fig. 6에 나타낸 바와 같이

Table 1 Comparison of chemical compos ition \%wt (ASME code/Mill sheet)

\begin{tabular}{|c|c|c|c|c|c|c|c|c|c|c|c|}
\hline Material & $\mathrm{C}$ & $\mathrm{Si}$ & $\mathrm{Mn}$ & $\mathrm{P}$ & $\mathrm{S}$ & $\mathrm{Cu}$ & $\mathrm{Al}$ & $\mathrm{Ni}$ & $\mathrm{Cr}$ & $\mathrm{Mo}$ & $\mathrm{V}$ \\
\hline $\begin{array}{c}\text { SA302 } \\
\text { Grade B })\end{array}$ & $\begin{array}{c}0.23 \\
(0.18)\end{array}$ & $\begin{array}{c}0.13 \sim 0.45 \\
(0.22)\end{array}$ & $\begin{array}{c}1.07 \sim 1.62 \\
(1.31)\end{array}$ & $\begin{array}{c}0.035 \\
(0.06)\end{array}$ & $\begin{array}{c}0.035 \\
(0.01)\end{array}$ & $\begin{array}{c}- \\
(0.21)\end{array}$ & $\begin{array}{c}- \\
(0.032)\end{array}$ & $\begin{array}{c}- \\
(0.19)\end{array}$ & $\begin{array}{c}- \\
(0.18)\end{array}$ & $\begin{array}{c}0.41 \sim 0.64 \\
(0.5)\end{array}$ & $\begin{array}{c}- \\
(0.002)\end{array}$ \\
\hline $\begin{array}{c}\text { SA516 } \\
\text { (Grade 60) }\end{array}$ & $\sim 0.23$ & $0.13 \sim 0.45$ & $0.55 \sim 0.98$ & $\sim 0.035$ & $\sim 0.035$ & - & - & - & - & - & - \\
\hline SA106 & $\sim 0.35$ & $\begin{array}{c}0.1 \sim \\
(0.224)\end{array}$ & $\begin{array}{c}0.2 \sim 1.06 \\
(1.03)\end{array}$ & $\begin{array}{c}\sim 0.035 \\
(0.013)\end{array}$ & $\begin{array}{c}\sim 0.035 \\
(0.003)\end{array}$ & $\begin{array}{c}\sim 0.4 \\
(0.014)\end{array}$ & - & $\begin{array}{c}0.4 \\
(0.01)\end{array}$ & $\begin{array}{c}\sim 0.4 \\
(0.02)\end{array}$ & $\begin{array}{c}\sim 0.15 \\
(-)\end{array}$ & $\begin{array}{c}\sim 0.08 \\
(0.001)\end{array}$ \\
\hline
\end{tabular}




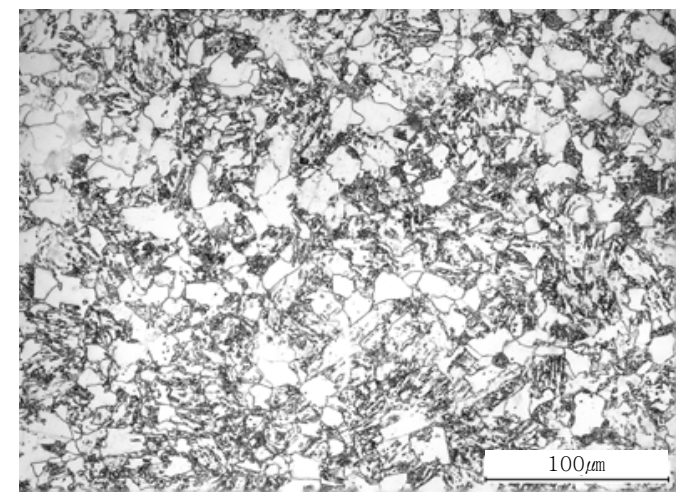

Fig. 4 Optical micrograph $(\times 400)$ of SA302GrB

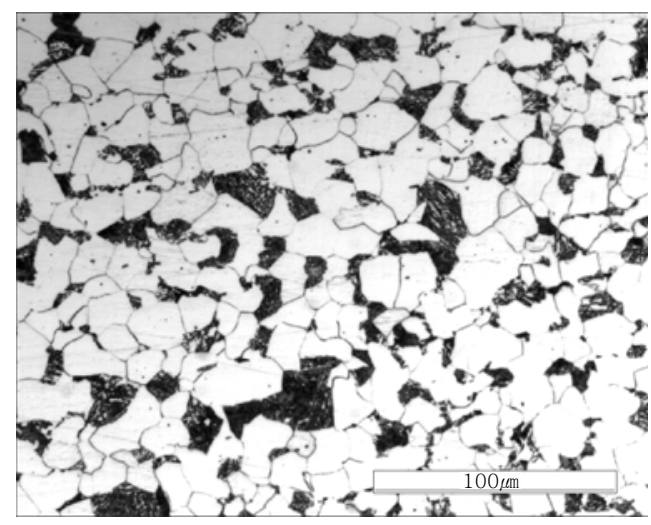

Fig. 5 Optical micrograph $(\times 400)$ of SA516-60

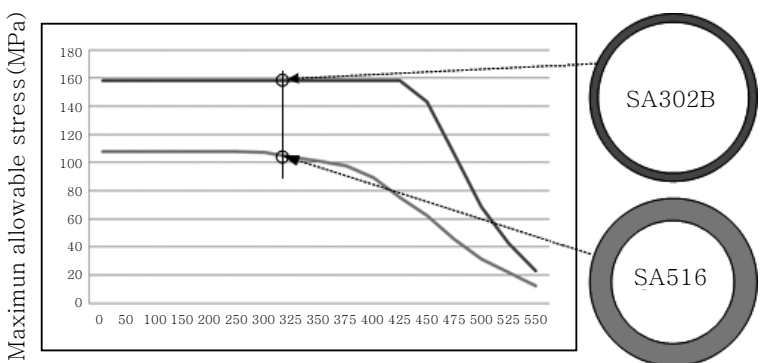

Fig. 6 Comparison of minimum thickness for the materials

고온강도 측면에서는 약 $40 \%$ 정도의 두께감소가 가능 하여 경제성면에서 우수한 것을 알 수 있다.

\section{3 제작공정 검토}

손상된 스팀드럼의 용접방법은 Table 3에서 나타낸 바와 같이 플럭스코어드용접 (FCAW)을 적용하여 $\mathrm{SFA}^{-}$ $5.20 \mathrm{E} 71 \mathrm{~T}-1 \mathrm{C}$ 와이어를 사용하였다. Table 4에서 나타낸 용접조건와 같이 용접 예열과 강판 절곡시의 온 도는 $\mathrm{P}-3$ 을 기준 $\left(\min .95^{\circ} \mathrm{C}\right)$ 으로 하였고 예열방법은 토치를 이용한 화염 예열방법을 적용하였으며 에지
Table 3 Chemical composition of the electrode element (wt-\%)

\begin{tabular}{|c|c|c|c|c|c|c|c|}
\hline Wire & C & $\mathrm{Cr}$ & Mo & $\mathrm{Mn}$ & $\mathrm{Si}$ & $\mathrm{P}$ & S \\
\hline $\begin{array}{l}\text { SFA-5.20 } \\
\text { E71T-1C }\end{array}$ & 0.06 & 0.03 & 0.01 & 1.28 & 0.56 & 0.015 & 0.012 \\
\hline Specification & $\tilde{0.12}$ & $\underset{0.20}{\sim}$ & $\tilde{0.30}$ & $\underset{1.75}{\sim}$ & $\tilde{0.90}$ & $\underset{0.03}{\sim}$ & $\tilde{0.03}$ \\
\hline
\end{tabular}

Table 4 Welding parameters

\begin{tabular}{|c|c|c|c|}
\hline $\begin{array}{c}\text { Electrode } \\
\text { dia }(\mathrm{mm})\end{array}$ & $\begin{array}{c}\text { Preheat } \\
\text { temp }\left({ }^{\circ} \mathrm{C}\right)\end{array}$ & P.W.H.T $\left({ }^{\circ} \mathrm{C}\right)$ & $\begin{array}{c}\text { Current } \\
\text { (A) }\end{array}$ \\
\hline 1.4 & Min. 95 & $600 \sim 650$ & $150 \sim 400$ \\
\hline Voltage $(\mathrm{V})$ & $\begin{array}{c}\text { Welding } \\
\text { speed }\end{array}$ & Bead tech & P-No \\
\hline $23 \sim 37$ & $\begin{array}{c}10 \sim 45 \\
(\mathrm{~cm} / \mathrm{min})\end{array}$ & $\begin{array}{c}\text { Stringer \& } \\
\text { Weave }\end{array}$ & $\begin{array}{c}\text { P-No 1 Gr 1 } \\
\text { to P-No 3 Gr 1 }\end{array}$ \\
\hline
\end{tabular}

(Edge) 및 롤벤딩 후 풀림 열처리 없이 바로 셀에 노 즐을 용접하였다.

\section{3. 시험 및 고찰}

\section{1 육안 검사}

Fig. 7에서 나타낸 바와 같이 셀에 노즐을 용접한 후 약 1 주일 후에 셀측 용접 열영향부에서 지연파괴(delayed fracture)되어, 최초모재에서 표면균열이 발생, 내부로 진행되었고(설계두께: $75 \mathrm{t}$, 균열깊이:73t $(\mathrm{Max})$ ) 모 재를 따라 취성파괴(brittle fracture) 형태로 진행하 였다. 비파괴검사(magnetic particle test) 결과 Fig. 8 에서와 같이 다수의 노즐 용접부에서 미세균열이 발생 되었다. 균열이 발생된 지역은 공통적으로 노즐 사이 피 치가 좁게 설계되어 겹침 용접된 셀측 열영향부이며 균열 유형은 토우(Toe) 및 횡균열(Longitudinal crack) 형 태로 진행되었다.

\section{2 미세조직 시험}

표면복제를 통한 조직검사결과 균열은 Fig. 9에서 나 타낸 바와 같이 $\mathrm{SA} 302 \mathrm{~B}$ 측 본드라인/열영향부 경계에 따라 발생되었고, 미세조직은 기존 페라이트와 베이나 이트 혼합조직에서 취성조직인 마르텐사이트으로 변태 된 것을 확인 할 수 있었다. 이는 용접과정에서 예열미 비 등의 이유로 급냉이 발생되어 취성조직으로 변환되 었다고 판단할 수 있다. 


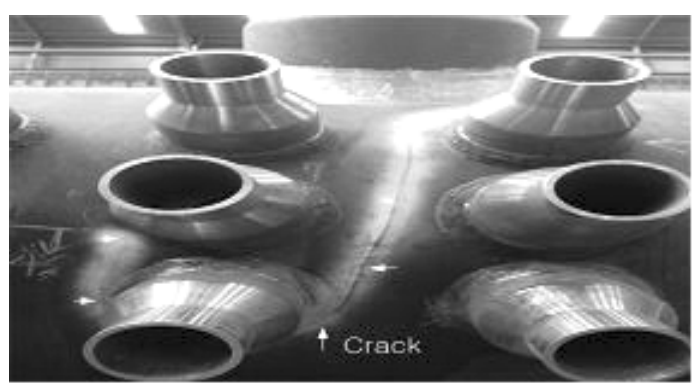

Fig. 7 Main crack on base metal \& HAZ

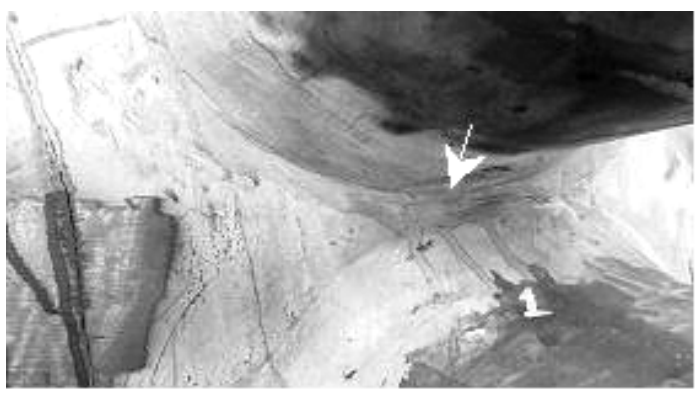

Fig. 8 Cross weld metal area HAZ crack

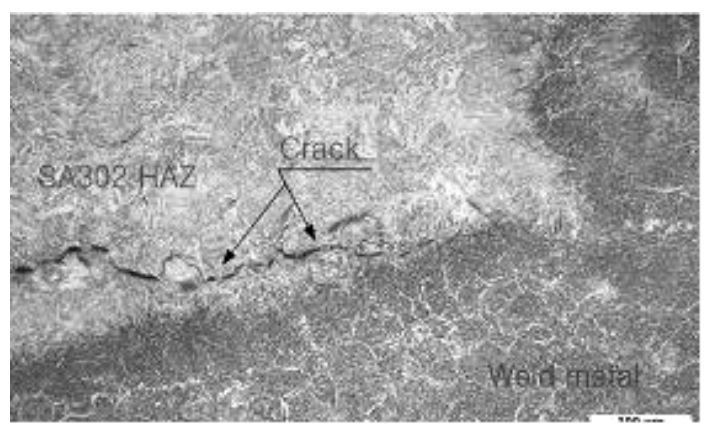

Fig. 9 Base metal HAZ crack by optical micrograph $(\times 400)$ of $\mathrm{SA} 302 \mathrm{GrB}$

\section{3 경도 시험}

휴대용경도기(초음파경도계)를 이용하여 손상된 셀에 노즐을 용접한 용접열영향부 및 용착금속의 경도를 검 사한 결과인 Table 5 에 나타낸 바와 같이, 최대 226 $\mathrm{Hv}$ 을 나타낸 점을 감안하면, 판재 절곡 가공 중 가공

Table 5 Hardness data

\begin{tabular}{|c|c|c|}
\hline \multicolumn{2}{|c|}{ 구 분 } & $\mathrm{Hv}$ (5회 측정평균) \\
\hline \multirow{2}{*}{ No.1 } & Base Metal & 209 \\
\cline { 2 - 3 } & Weld Metal & 157 \\
\hline \multirow{2}{*}{ No.2 } & Base Metal & 226 \\
\cline { 2 - 3 } & Weld Metal & 157 \\
\hline \multirow{2}{*}{ No.3 } & Base Metal & 226 \\
\cline { 2 - 3 } & Weld Metal & 157 \\
\hline
\end{tabular}

Table 6 Comparison of mechanical properties on as-received and after bending

\begin{tabular}{|c|c|c|c|c|}
\hline Material & $\begin{array}{c}\mathrm{YS} \\
(\mathrm{MPa})\end{array}$ & $\begin{array}{c}\mathrm{TS} \\
(\mathrm{MPa})\end{array}$ & $\begin{array}{c}\text { E.I } \\
(\%)\end{array}$ & 비고 \\
\hline \multirow{2}{*}{ SA302B } & $345 \sim$ & $550 \sim 690$ & 15 & ASME code \\
\cline { 2 - 5 } & 550 & 681 & 25 & As-receive \\
\cline { 2 - 5 } & 594 & 716 & 24 & After bending \\
\hline SA516-60 & $220 \sim$ & $415 \sim 550$ & 21 & ASME code \\
\hline
\end{tabular}

경화 누적 및 용접과정에서 마르텐사이트 변태에 의한 것으로 추정할 수 있다.

\section{4. 손상원인 분석}

\section{1 용접절차서 문제점}

SA302B 소재는 ASME IX QW 422의 재료분류에 서 $\mathrm{P} 3$ 로 지정되어 있어 예열온도가 $95^{\circ} \mathrm{C}(\mathrm{Min})$ 로 설계 하였으나, Table 1 의 화학성분과 같이 석출경화형 원 소 $(\mathrm{Cu}, \mathrm{Al}, \mathrm{V}, \mathrm{Ti})$ 가 포함된 소재이다. 그러나 Table 6 에서 나타낸 입수 상태의 인장강도가 코드규격의 상한 치에 근접하여 있고, 판재 절곡 후 인장강도의 규격이 초과되는 고강도 소재인 점을 감안하면, $\mathrm{P} 5$ 로 상향하 여 예열을 최소 $150^{\circ} \mathrm{C}$ 이상으로 시행할 필요가 있었다 고 생각된다. 따라서 낮은 예열온도로 인한 경화조직으 로의 변태와 이로 인한 잔류인장응력의 증가와 수소취 성 문제가 발생되었다고 판단된다.

\section{2 용접구조설계 문제점}

균열이 발생된 지역은 공통적으로 셀/노즐의 겹침 용 접열영향부에서 발생되었고, Fig. 10에서의 유사손상 사례와 같이 겹침용접은 응고수축 잔류인장응력이 과다 집중되며, 입열량(heat input) 증가로 인하여 결정립 이 성장하는 문제가 발생된다. 그러나 설계과정에서 노 즐 간의 피치를 크게 하여 겹침 용접을 제한해야 하는 데 이를 감안하지 않았기 때문에 주요 손상원인으로 된 것으로 사료된다.

\subsection{Plate 절곡공정 문제점}

SA302B 소재 인장특성은 Table 6에서 나타낸 바와 같이 절곡과정 중에 가공경화 효과가 커서 본 용접시행 이전에 응력제거풀림처리 시행이 매우 중요한 공정이나 (edge bending후, forming 후 열처리 최소2회) 미 

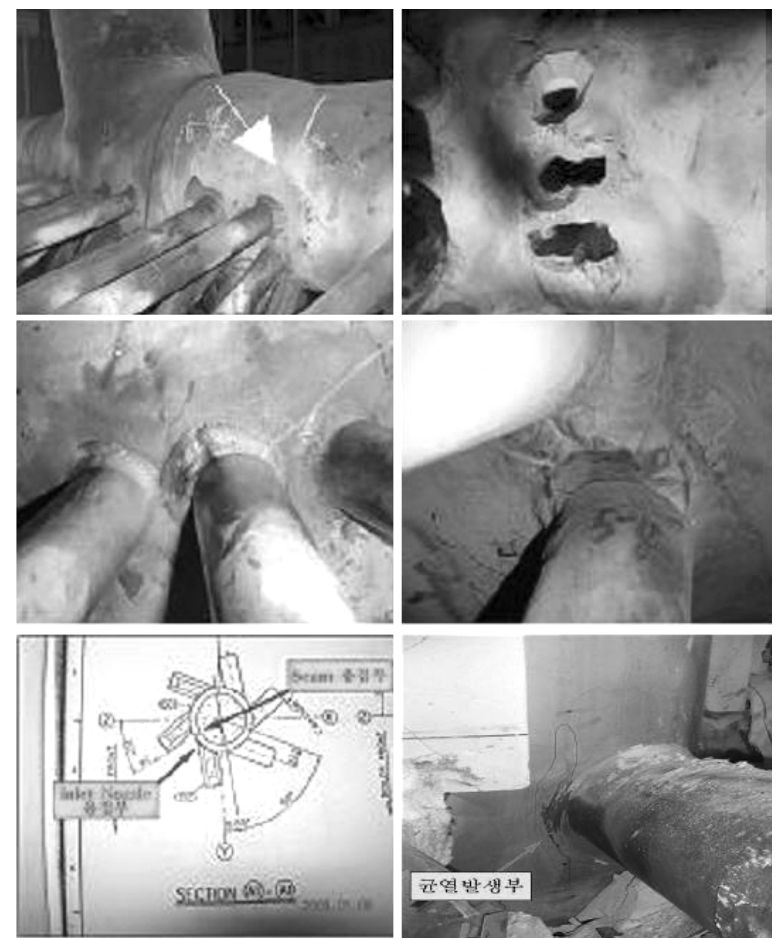

Fig. 10 Example failures on narrow weld-joint and cross weld metal ${ }^{4)}$

시행에 따른 가공잔류응력이 추가로 모재에 부과되어 손상원인으로 제공되었다.

\section{4 용접시공 문제점}

용접 후 일정기간 경과 후 균열이 발생된 점을 감안 하고 용접금속에 습분유입이 용이한 $\mathrm{FCAW}$ 를 사용하

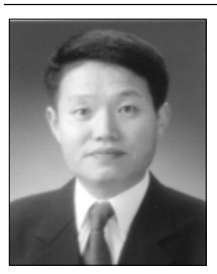

- 안종석

-1962년생

- Hanyang University

- Mechanical Engineering

-e-mail: ahnjs001@ewp.co.kr

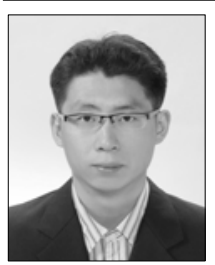

- 윤재연

-1979년생

- Inje University

- Mechanical Engineering

•e-mail:06170307@ewp.co.kr
였고, 화염토치에 의한 예열 방법 등의 시공방법을 종 합하면, 일정한 예열온도의 유지 실패로 인한 급냉 및 수분 유입으로 지체균열(Delay crack ; (hydrogen embrittlement crack)의한 손상이 발생 되었다고 판 단된다.

\section{5. 결 론}

석탄화력 발전용 보일러 스팀드럼에 신규로 적용된 저 합금강판(SA302B) 용접부의 손상원인에 대한 분석 결과,

1) 고강도 소재인 점을 감안하면 예열온도를 $\mathrm{P} 5$ 를 기준으로 하여 최소 $150^{\circ} \mathrm{C}$ 을 유지해야한다.

2) 인접 용접부와 겹침 용접을 방지하기 위해 충분한 이격공간이 갖도록 한 용접구조 설계가 필요하다.

3) 절곡가공경화 효과가 큰 소재로서 본 용접시행 전 에 반드시 응력제거풀림처리가 필요로 한다.

4) 일정예열 온도유지를 위한 기존 Flame방법에서 전기패드방식으로 예열방법의 개선과 용접봉 건조 등 절차 절차준수와 비파괴검사의 강화시행이 필요로 한다.

\section{참 고 문 헌}

1. 용접·접합편람 $\Pi$ I : 대한용접 - 접합학회, 2008 297 298 (in Korean)

2. 용접·접합편람 I : 대한용접·접합학회, 200850 51 (in Korean)

3. 용접·접합편람 I : 대한용접·접합학회, 200836 48 (in Korean)

4. 대한용접접합학회지 : 28권1호 2010.2, 44 